\section{Volume perfusion computed tomography as an aid to diagnosis of pancreatic tuberculosis}

\section{Introduction}

Abdominal tuberculosis (TB) includes infection anywhere in the gastrointestinal tract, peritoneum, mesentery and intraabdominal organs such as the spleen, liver and pancreas. Isolated pancreatic involvement is extremely rare and the exact incidence is unknown. We present two cases of pancreatic tuberculosis with varied clinical and radiological features.

\section{Case reports}

Case 1

A 24-year-old female patient presented with two months history of abdominal pain, jaundice, pruritus, anorexia, significant weight loss, clay colored stool and occasional low grade fever. There was no history of cough, hemoptysis, night sweats or difficulty in breathing. There was no past history of TB. On examination, she was anemic and icteric with scratch marks over the body. Laboratory investigation revealed a hemoglobin of $10 \mathrm{~g} / \mathrm{dl}$ (normal: $12 \pm 2 \mathrm{~g} / \mathrm{dl}$ ); WBC count of $8500 / \mathrm{mm}^{3}$; differential count of $84 \%$ neutrophils, $16 \%$ lymphocytes; total bilirubin of $2.5 \mathrm{mg} / \mathrm{dl}$ (normal: 0.2-1 mg/dl); conjugated bilirubin of $1.8 \mathrm{mg} / \mathrm{dl}$; alanine transaminase of $198 \mathrm{U} / \mathrm{L}$ (normal: 5-40 U/ L); aspartate transaminase of $240 \mathrm{U} / \mathrm{L}$ (normal: 5-43 U/L), and alkaline phosphatase of $1257 \mathrm{U} / \mathrm{L}$ (normal: 60-128 U/L), albumin of $3.9 \mathrm{~g} / \mathrm{dl}$ (normal: $3.5-5 \mathrm{~g} / \mathrm{dl}$ ) and total protein of $7.7 \mathrm{~g} / \mathrm{dl}$ (normal: 6.1- $8.3 \mathrm{~g} / \mathrm{dl}$ ).. Chest radiograph was also normal. Abdominal ultrasound revealed a large heteroechoic lesion of $3.5 \times 3.0 \mathrm{~cm}$ in size, in the head and uncinate process of pancreas, with dilated main pancreatic duct (MPD). There was associated bilobar intrahepatic biliary dilatation (IHBRD) with dilated common bile duct (CBD) up till the pancreatic head region. Volume Perfusion Computed Tomography (VPCT) (Figure 1) revealed an ill-defined hypodense mass lesion measuring $3.7 \times$ $3.2 \mathrm{~cm}$, in the pancreatic head and uncinate process, abutting the superior mesenteric vein (SMV) with dilated MPD distal to the mass. There was bilobar IHBRD with dilated CBD up till the pancreatic head region, with a distended gall bladder. There was no associated retroperitoneal or mesenteric lymphadenopathy, thickened bowel loops, omental thickening

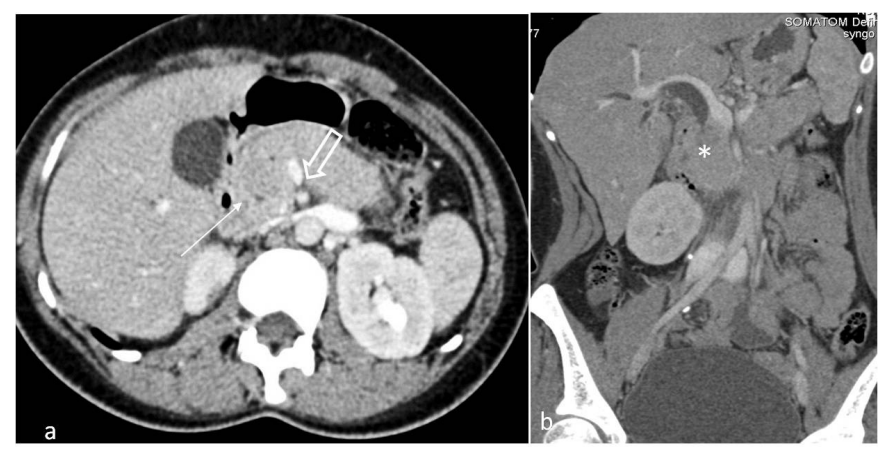

Figure 1: a) Axial and b) reformatted coronal images of contrastenhanced CT scan in portal venous phase, showing an illdefined hypodense mass in the pancreatic head (thin arrow) causing abrupt cut-off of the CBD (*) and MPD (not shown) with proximal dilatation. The mass is showing $180^{\circ}$ abutment with SMV inducing a tear drop appearance (outlined arrow)

or ascites. Perfusion parameters were calculated for the pancreatic head lesion (Figure 2) of which blood flow (BF), blood volume (BV) and peak enhancement intensity (PEI) were reduced compared to the normal body and tail of
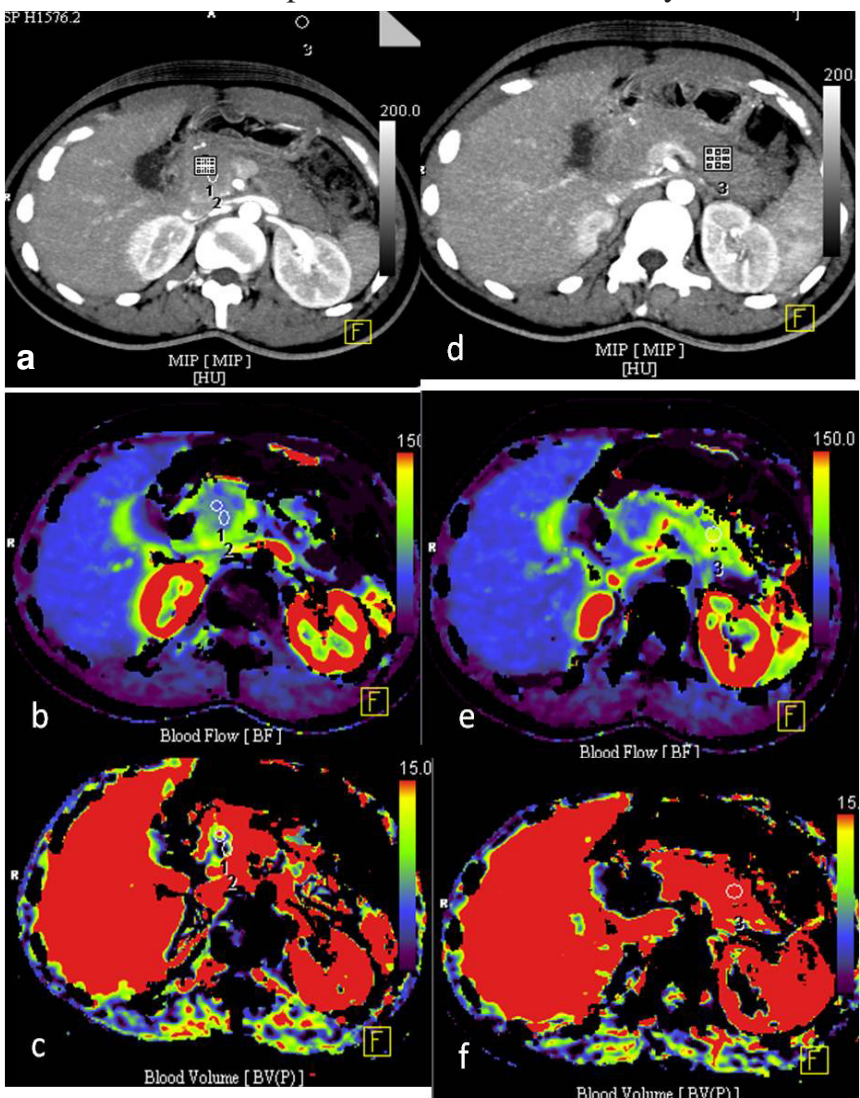

Figure 2: VPCT perfusion map of the pancreatic head mass (ROI$1,2)$ and normal pancreatic tail (ROI-3); PEI map (a,d), BF map (b, e), and BV map (c, f). Red color represents high values and purple represents low values of perfusion parameters. There is marked reduction in perfusion parameters in the pancreatic head mass (a-c) in comparison to the normal pancreas (d-f). 
Table 1: Volume Perfusion Computed Tomography perfusion parameters of Case 1

\begin{tabular}{llll}
\hline Parameters & $\begin{array}{l}\text { ROI-1 } \\
\text { (Pancreatic } \\
\text { head mass) }\end{array}$ & $\begin{array}{l}\text { ROI-2 } \\
\text { (Pancreatic } \\
\text { head mass) }\end{array}$ & $\begin{array}{l}\text { ROI-3 } \\
\text { (Normal } \\
\text { pancreas) }\end{array}$ \\
\hline PEI $(\mathrm{HU})$ & 98.78 & 97.27 & 132.98 \\
$\mathrm{BF}(\mathrm{ml} / 100 \mathrm{gm} / \mathrm{min})$ & 50.46 & 54.78 & 109.19 \\
$\mathrm{BV}(\mathrm{ml} / 100 \mathrm{gm})$ & 10.32 & 8.89 & 44.78 \\
\hline
\end{tabular}

pancreas (Table 1).

In view of the clinical setting and radiological features, the possibility of pancreatic carcinoma was considered. As the lesion was resectable, laparotomy was performed and on-table frozen section showed multiple necrotizing epitheloid cell granulomas with lymphocytic infiltration and destruction of pancreatic acini with marked fibrosis. The surgical plan was changed from a Whipple's resection to a Roun-en-Y hepaticojejunostomy to relieve CBD obstruction. Based on the histopathological findings, a diagnosis of pancreatic tuberculosis was made and the patient was treated with antitubercular therapy (ATT). Significant clinical improvement was noted within two months and follow-up transabdominal sonography (Figure 3) showed marked reduction in size of the pancreatic head mass.

\section{Case 2}

A 35-year-old male patient presented with four months history of abdominal pain, anorexia and significant weight loss. There was no history of fever, cough, hemoptysis, night sweats, difficulty in breathing, jaundice or prior TB. Laboratory

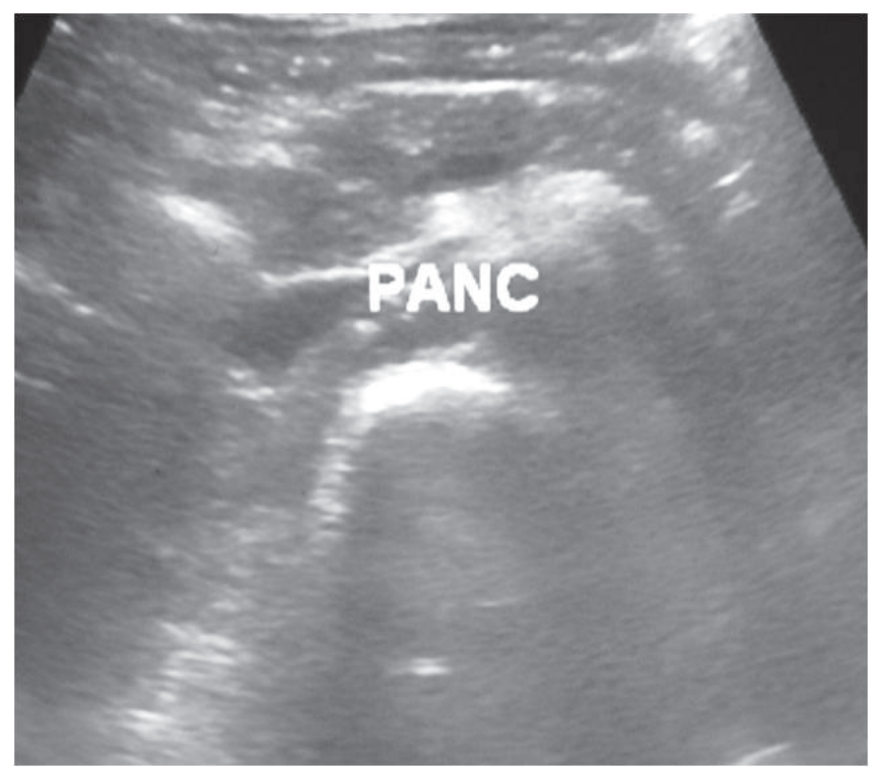

Figure 3: Follow-up ultrasound abdomen shows no mass lesion in the head of pancreas investigation revealed a hemoglobin of $12 \mathrm{~g} / \mathrm{dl}$ (normal: $14 \pm 2$ $\mathrm{g} / \mathrm{dl}$ ); WBC count of $7800 / \mathrm{mm}^{3}$; differential count of $80 \%$ neutrophils and $20 \%$ lymphocytes; total bilirubin of $0.7 \mathrm{mg} / \mathrm{dl}$ (normal: $0.2-1 \mathrm{mg} / \mathrm{dl}$ ), alanine transaminase of $32 \mathrm{U} / \mathrm{L}$ (normal: 5-40 U/L), aspartate transaminase of $23 \mathrm{U} / \mathrm{L}$ (normal: 5-43 U/L), and alkaline phosphatase of $120 \mathrm{U} / \mathrm{L}$ (normal: 60-128 U/L), albumin of $5.0 \mathrm{~g} / \mathrm{dl}$ (normal: $3.5-5 \mathrm{~g} / \mathrm{dl}$ ) and total protein of 7.5 $\mathrm{g} / \mathrm{dl}$ (normal: 6.1-8.3 g/dl). Chest radiograph was normal. Abdominal ultrasound revealed multiple hypoechoic lesions in the body and tail of pancreas. CECT (Figure 4) revealed multiple hypodense lesions, largest measuring $2.1 \times 2.2 \mathrm{~cm}$,

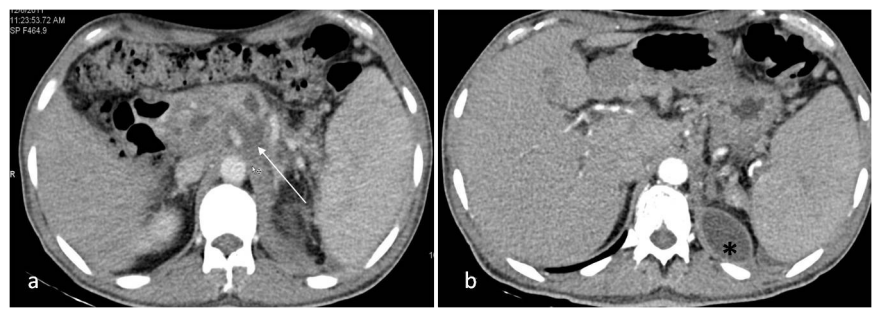

Figure 4: Axial contrast-enhanced CT images show multiple hypodense lesions in pancreas, largest of which is in the body of pancreas encasing the celiac axis and its branches (thin arrow). Also a well defined left subdiaphragmatic collection $(*)$ and small perisplenic collection are noted.
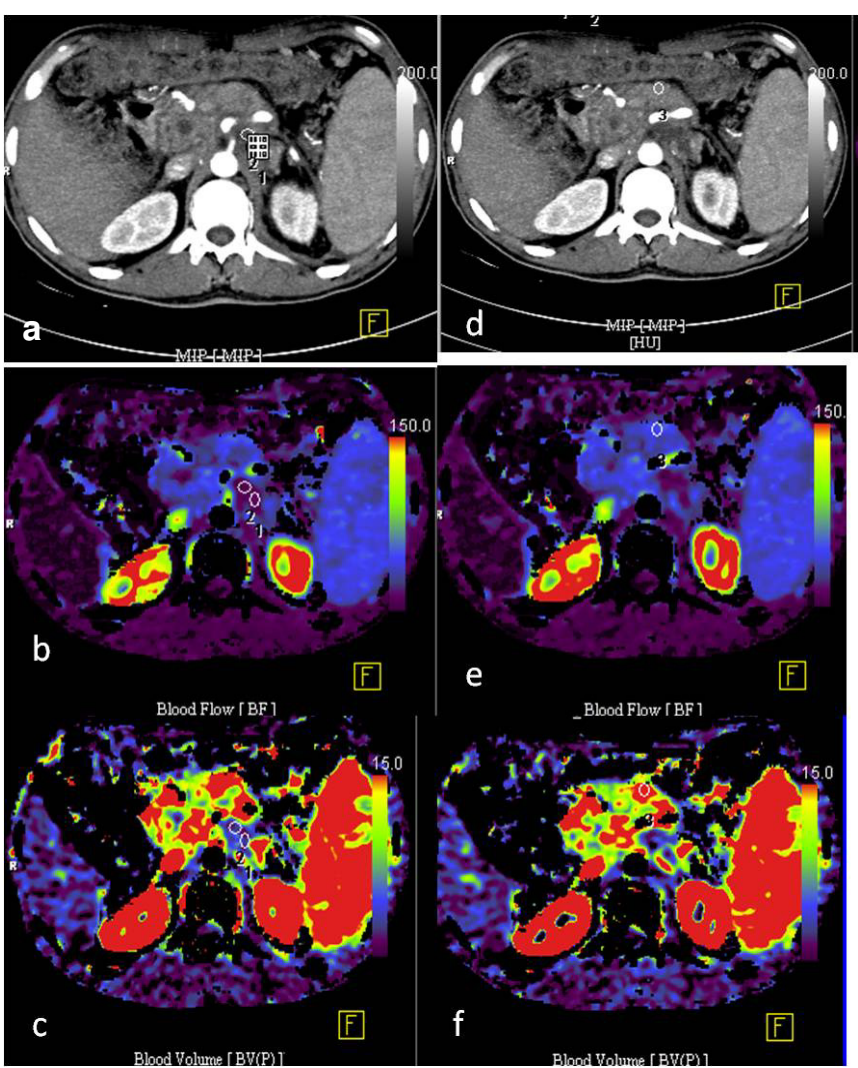

Figure 5: VPCT perfusion map of the pancreatic mass (ROI- 1,2) and normal part of the pancreas (ROI-3); PEI map (a, d), BF map (b, e), and BV map (c, f). There is marked reduction in perfusion parameters in pancreatic body mass (a-c) in comparison to normal pancreas (d-f). 
Table 2: Volume Perfusion Computed Tomography perfusion parameters of Case 2

\begin{tabular}{llll}
\hline Parameters & $\begin{array}{l}\text { ROI-1 } \\
\text { (Pancreatic } \\
\text { body mass) }\end{array}$ & $\begin{array}{l}\text { ROI-2 } \\
\text { (Pancreatic } \\
\text { body mass) }\end{array}$ & $\begin{array}{l}\text { ROI-3 } \\
\text { (Normal } \\
\text { pancreas) }\end{array}$ \\
\hline PEI $(\mathrm{HU})$ & 57.05 & 63.32 & 110.33 \\
$\mathrm{BF}(\mathrm{ml} / 100 \mathrm{gm} / \mathrm{min})$ & 11.59 & 8.12 & 51.68 \\
$\mathrm{BV}(\mathrm{ml} / 100 \mathrm{gm})$ & 2.82 & 3.07 & 20.76 \\
\hline
\end{tabular}

encasing the celiac axis and its branches in the pancreatic body region. There was peri-pancreatic fat stranding and thickening of renal fascia with a contiguous subdiaphragmatic collection on left side. There was no associated retroperitoneal or mesenteric lymphadenopathy, thickened bowel loops, omental thickening or ascites. Perfusion parameters (PEI, BF and BV) of the pancreatic lesions were (Figure 5) significantly reduced compared to the normal enhancing pancreas (Table 2). In view of encasement of the celiac axis by the pancreatic lesion, a ultrasound guided percutaneous FNAC was advised to confirm the nature of the lesion. FNAC revealed multiple necrotizing epitheloid cell granulomas with lymphocytic infiltration. A diagnosis of pancreatic tuberculosis was made and the patient was treated with ATT. On follow-up, significant improvement was seen both clinically and on imaging (ultrasound revealed decrease in size of pancreatic lesions).

\section{Discussion}

Isolated pancreatic involvement in tuberculosis is extremely rare probably because of the protective effect of pancreatic enzymes against mycobacteria which interferes with their seeding. ${ }^{1,2}$ Pancreatic TB is commonly seen in young patients, with female predominance, and past history of TB or in TB endemic regions. ${ }^{3}$ The first line non-invasive imaging modalities for pancreatic pathology include ultrasound and CT. Ultrasound may reveal focal hypoechoic or hypo- to isoechoic lesion or cystic collection most often in the body of pancreas followed by head and tail. ${ }^{2} \mathrm{CT}$ may show hypodense or cystic lesions in the pancreas, with features of acute or chronic pancreatitis and necrotic retroperitoneal or mesenteric lymphadenopathy along with bowel wall thickening and ascites. One of our patients presented with a hypodense mass in pancreatic head mimicking pancreatic carcinoma while the other had hypodense lesions in distal body and tail of pancreas with adjacent fascial thickening mimicking pancreatitis.

Volume perfusion CT is a new and upcoming modality which can quantify perfusion at microvascular level by measuring temporal changes in attenuation. VPCT was performed in both these cases and it showed reduction of blood flow and blood volume in the lesions as compared to normal pancreas (Tables 1 and 2). Perfusion parameters are also reduced in pancreatic cancer however the extent of reduction is much more than in a pancreatic tubercular mass. To the best of our knowledge perfusion CT findings in pancreatic tuberculosis have not been published in literature. VPCT parameters may enable differentiation between pancreatic cancer and pancreatic tuberculosis, although further studies are needed to establish the statistical significance of differences in perfusion parameters.

AJAY KUMAR YADAV ${ }^{1}$

JEYASEELAN NADARAJAH ${ }^{1}$ DEVASENATHIPATHY KANDASAMY ${ }^{1}$

RAJU SHARMA ${ }^{1}$

SHIVANAND GAMANAGATTI ${ }^{1}$ PRAMOD KUMAR GARG ${ }^{2}$

Correspondence: Dr Raju Sharma Departments of Radiodiagnosis ${ }^{1}$ and Gastroenterology, ${ }^{2}$ All India Institute of Medical Sciences, New Delhi - 110029, India Email:raju152@yahoo.com

\section{References}

1. Khaniya S, Koirala R, Shakya VC, Adhikary S, Regmi R, Pandey $\mathrm{SR}$, et al. Isolated pancreatic tuberculosis mimicking as carcinoma: a case report and review of the literature. Cases J. 2010;3:18.

2. Nagar AM, Raut AA, Morani AC, Sanghvi DA, Desai CS, Thapar VB. Pancreatic tuberculosis: a clinical and imaging review of 32 cases. J Comput Assist Tomogr. 2009;33:136-41.

3. Xia F, Poon RT, Wang SG, Bie P, Huang XQ, Dong JH. Tuberculosis of pancreas and peripancreatic lymph nodes in immunocompetent patients: experience from China. World $J$ Gastroenterol. 2003;9:1361-4.

\section{Colonic spirochetosis in an immunocompetent child}

\section{Introduction}

This is the first case report of colonic spirochetosis from a tropical country like India. Clinicians should consider rare 